\title{
The Alignment Between Business Objectives Clarity and Software Objectives
}

\author{
MOHAMMAD MAHMOUD TARAWNEH \\ Al-Balqa Applied University /karak University Collage
}

\begin{abstract}
This paper aims to highlight a very important concept and plays a key role in the success of software development, which is the alignment between business objectives and software objectives. In this research we refer to most of the literature that dealt with this subject. The researcher designed a questionnaire and conducted field interviews with software project managers. This study concluded with a set of recommendations and found that the alignment between business objectives and software goals plays a prominent role in software development and has a positive impact on the success of the software.
\end{abstract}

Keywords: business objective, software objective, software development, alignment

DOI: $10.7176 / \mathrm{CEIS} / 10-2-04$

Publication date:March $31^{\text {st }} 2019$

\section{Introduction}

In the software development market Harmonize business objectives with software project management, Objectives of action at the organization level reflect the company's vision, which platform like improving / maintaining customers / stakeholders Satisfaction and market share. At the organizational level, an effective job management system was established Such as on critical areas of financial success, effective use of resources, and analysis of market potential Opportunities for innovation and development. The organizational management system will not guarantee organizational success. If there is no clear strategy translated into a set of clear operational objectives, executives must have the ability to map the organization's objectives to the objectives of the software project at all operational levels. This will help to ensure that all objectives are aligned at all organizational levels. This may occur when identified on the software at the operational level. This will help to synchronize the organization's strategies, competitiveness and program objectives such as increasing product reliability and reducing the development schedule. One of the errors in software organizations at the level of the software project is the higher levels of maturity, where the measurement of the main performance indicators as a final goal is considered to be isolated from the indicators of the organizational level, so follow the strategies associated with business objectives and this requires a great effort at all stages of the software project To produce the expected benefits especially since the goals usually remain unclear (Chrissis et al., 2007).

The alignment between the clarity of purpose of business organizations and the software industry has long been a concern for practitioners and academics alike. (Kruger, 2012; Brown \& Motjolopane, 2005).

Four main characteristics of the problem of alignment business and software integration can be seen. First, it is an urgent priority for software and IT managers (Chen, 2010:9; Jorfi, Nor \& Najjar, 2011). The second thing is that it is consistently the top priority in the project (Mpazanje, 2013. The third is the belief that business organizations do not create competitiveness without a harmonious work between them (Jorfi et al., 2011). Finally, the process of alignment between business and software industry is difficult to achieve (Karpovsky \& Galliers:2015). The question that arises is the fact that the process of compatibility and compatibility between the work and the software industry is complex, why continue to academics and those interested in follow-up? Studies have shown that the compatibility and compatibility between business and the software industry and information technology improve the performance of organizations (Brown \& Motjolopane, 2005; Cohen \& Toleman, 2006).

Therefore, this paper focuses on the extent of the correlation between the clarity of business and its impact on the development of the software industry and whether this development contributes to the development of organizations. For this purpose, the researcher designed a questionnaire distributed to 100 managers of software projects. Fifteen managers were selected and interviewed to determine the impact of the business objectives on the development of the software industry in the Jordanian environment

\section{Related Work}

According to Boehm and Ross (1989) Having a clear goal for a software project and being a collaborator with a business goal plays a role in software success. They said that the existence of two different teams in different objectives, one dealing with the requirements of users and the other team dealing with technical matters, this difference will lead to misunderstanding and identify the objectives of the project and thus will play a role in the failure of the software project. Another The planning cycle starts by formation the goals and objectives and determining the requirements for the system. The objectives give over-all project direction, also help to define the deliverables which is attached result delivered upon task completion. There are many different formats, eg 
computer file, reports or user directory. It is essential that there be a clear objective challenge to all developments that are unequivocal. There are many approaches that try to match the measurement at the business level and the level of programs, a combination of business addresses (PSM, GQM, BSC), Well-known methods of measurement, i.e., the mismatch between the strategy at the organizational level and the organizational objectives. This leads to operational failure through processes and standards at the project level (Becker and Bostelman's 1999).

There is a consensus among authors to establish a framework for measuring and supporting the alignment of organizational objectives and the level of software projects so that the terminology surrounding the targets is included and aligned at all levels so that relative visions of one target are acquired at a single level so that each level shares the same objectives. Buglione and Abran (2000) They found it The main differences between BSC and GQM lie in the subject of measurement (BSC focuses on organization While GQM is more focused on the project), the nature of the approach (GQM is a project measurement technique) While the BSC is a comprehensive framework), the approach of integration of organizational strategy (BSC Broadly integrate organizational strategy and objectives while not GQM). 2001).

According to Standish group report in 2001 it take fourth rank, it one of manger responsibility (Extreme chaos,

Boehm and Ross (1989) pointed out that the present of two different team in software development with two different objective, one deal with user requirement and another deal with technical challenges this lead to misunderstanding of objectives for the project. Most of the previous literature shows and corrects a major problem in the performance of software, which is attributed to many academics and practitioners to a gap between business functions and the software industry. Finally, it is logical that workers in the software industry want to reduce that gap. Hence, the focus was on the compatibility between the business functions and the manufacture of its work of the things that occupied the researchers in ancient times (Kruger, 2012; Alter, 2008). Several previous studies have highlighted the alignment process between the clarity of business objectives and the clarity of software development objectives that are often used to obtain resources from organizations. It shows that many software projects are of strategic importance when they are ready to run. Most researchers stress the importance of compatibility and compatibility

According to Boehm and Ross (1989) Having a clear goal for a software project and being a collaborator with a business goal plays a role in software success. They said that the existence of two different teams in different objectives, one dealing with the requirements of users and the other team dealing with technical matters, this difference will lead to misunderstanding and identify the objectives of the project and thus will play a role in the failure of the software project. Another The planning cycle starts by formation the goals and objectives and determining the requirements for the system. The objectives give over-all project direction, also help to define the deliverables which is attached result delivered upon task completion. There are many different formats, eg computer file, reports or user directory. It is essential that there be a clear objective challenge to all developments that are unequivocal. There are many approaches that try to match the measurement at the business level and the level of programs, a combination of business addresses (PSM, GQM, BSC), Well-known methods of measurement, i.e., the mismatch between the strategy at the organizational level and the organizational objectives. This leads to operational failure through processes and standards at the project level (Becker and Bostelman's 1999).

There is a consensus among authors to establish a framework for measuring and supporting the alignment of organizational objectives and the level of software projects so that the terminology surrounding the targets is included and aligned at all levels so that relative visions of one target are acquired at a single level so that each level shares the same objectives. Buglione and Abran (2000) They found it The main differences between BSC and GQM lie in the subject of measurement (BSC focuses on organization While GQM is more focused on the project), the nature of the approach (GQM is a project measurement technique) While the BSC is a comprehensive framework), the approach of integration of organizational strategy (BSC Broadly integrate organizational strategy and objectives while not GQM). 2001).

According to Standish group report in 2001 it take fourth rank, it one of manger responsibility (Extreme chaos,

Boehm and Ross (1989) pointed out that the present of two different team in software development, with two different objective, one deal with user requirement and another deal with technical challenges this lead to misunderstanding of objectives for the project. Most of the previous literature shows and corrects a major problem in the performance of software, which is attributed to many academics and practitioners to a gap between business functions and the software industry. Finally, it is logical that workers in the software industry want to reduce that gap. Hence, the focus was on the compatibility between the business functions and the manufacture of its work of the things that occupied the researchers in ancient times (Kruger, 2012; Alter, 2008). Several previous studies have highlighted the alignment process between the clarity of business objectives and the clarity of software development objectives that are often used to obtain resources from organizations. It shows that many software projects are of strategic importance when they are ready to run. Most researchers stress the importance of compatibility and compatibility between the development of software and business, but this is difficult to verify 
and therefore is considered a waste of effort ( Parkinson 2002).

On the whole, previous studies confirm that the number of researchers who favour the alignment between business functions and software development is more than those who oppose it. Their arguments against the alignment between business objectives and software development can be refuted by multiple means. This leads us to the fact that there are additional reasons that push researchers and practitioners to do more and work in this area rather than abandon it.

\section{Data Analysis}

Table 1: Means and Standard Deviations of subjects' perceptions towards Clear and Define Objective factor

\begin{tabular}{|c|c|c|c|c|c|c|c|c|c|}
\hline \multirow[t]{2}{*}{ No } & \multirow[t]{2}{*}{ Problems } & \multicolumn{3}{|c|}{ Severity degree } & \multicolumn{3}{|c|}{ Frequency degree } & \multirow{2}{*}{$\begin{array}{l}\text { T- } \\
\text { Value }\end{array}$} & \multirow[t]{2}{*}{ Sig } \\
\hline & & Mean & Std & Severity & Mean & Std & Severity & & \\
\hline 4 & $\begin{array}{l}\text { There is a discussion } \\
\text { (agreement/rejection) about which } \\
\text { project will be chosen if there are } \\
\text { more than one project. }\end{array}$ & 3.63 & 0.94 & high & 3.58 & 0.92 & high & $14.24 *$ & 0.00 \\
\hline 20 & $\begin{array}{l}\text { Many tasks are assigned for few } \\
\text { individuals in teamwork }\end{array}$ & 354 & 0.98 & high & 3.51 & 0.96 & high & $12.00 *$ & 0.00 \\
\hline 21 & $\begin{array}{l}\text { Weakness of defining priorities } \\
\text { and tasks of project }\end{array}$ & 3.71 & 0.96 & high & 3.64 & 0.94 & high & $15.73^{*}$ & 0.00 \\
\hline 22 & $\begin{array}{l}\text { It is hard to know what the } \\
\text { appropriate task should be done } \\
\text { first in order to gain good result }\end{array}$ & 3.75 & 0.90 & high & 3.69 & 1.01 & high & $16.04 *$ & 0.00 \\
\hline 41 & $\begin{array}{l}\text { Plan of the project, budget, } \\
\text { variables or outcomes should be } \\
\text { redefined during the project to } \\
\text { develop the changeable plans of } \\
\text { the project }\end{array}$ & 3.58 & 0.97 & high & 3.54 & 0.97 & high & $13.04 *$ & 0.00 \\
\hline 73 & $\begin{array}{l}\text { Teamwork doesn't realize } \\
\text { measures and reports systems of } \\
\text { the project }\end{array}$ & 3.62 & 0.99 & high & 3.55 & 0,98 & high & $13.80 *$ & 0.00 \\
\hline 87 & $\begin{array}{l}\text { Teamwork do unnecessary things } \\
\text { which lead to increasing in cost and } \\
\text { extending of time }\end{array}$ & 3.60 & 0.89 & high & 3.56 & 0.99 & high & $13.54^{*}$ & 0.00 \\
\hline 88 & $\begin{array}{l}\text { Project's plan differs totally from } \\
\text { reality, but there is no change. }\end{array}$ & 3.52 & 0.99 & high & 3.50 & 1.02 & high & $10.75^{*}$ & 0.00 \\
\hline 91 & $\begin{array}{l}\text { There is a Lack of feedback which } \\
\text { means that degrees of success and } \\
\text { questioning are accepted equally. }\end{array}$ & 3.55 & 0.95 & high & 3.53 & 0.96 & high & $12.80 *$ & 0.00 \\
\hline & Total mean & 3.61 & 0.60 & high & 3.57 & 0.57 & high & $16.89 *$ & 0.00 \\
\hline
\end{tabular}

\section{*significant at level $(\alpha \geq 0.05)$}

Table (1) highlights that the variable clarity of the business objective in terms of intensity is (3.61) and the standard deviation $=(0.61)$ and element $(4)$, the answer is difficult to define the task to start first to reach an excellent result, When we find element (8): the starting plan in the first fact with the mean $=(3.75)$ and the standard deviation $=(0.99)$, there is no change in the last rank with an average of (3.52).

Table 2: Means And Percentages Of Define The Objective

\begin{tabular}{|c|l|c|c|c|}
\hline No & \multicolumn{1}{|c|}{ Item } & mean & percentage & Rank \\
\hline 1 & Employees know the required objectives & 12.58 & $62.90 \%$ & 4 \\
\hline 2 & $\begin{array}{l}\text { There are continuous meetings with executive administration } \\
\text { contribute to clarifying the objectives }\end{array}$ & 13.95 & $69.75 \%$ & 2 \\
\hline 3 & Employees have the opportunity to ask about what to do & 14.03 & $70.15 \%$ & 1 \\
\hline 4 & All activities help in achieving the wanted objectives & 13.54 & $67.70 \%$ & 3 \\
\hline
\end{tabular}

Identifying and clarifying the objective items came as the following arrangement: Employees have the opportunity to ask about what to do $(70.15 \%)$; there are continuous meetings with executive administration contribute to clarifying the objectives $(69.75 \%)$; all activities help in achieving the wanted objectives $(67.70 \%)$ and employees know the required objectives (62.90\%).

The clarity of the business objective plays an important role in determining the degree of success of the software engineering projects. When the goal is clear, it has the positive effect of facilitating the task of the software development team and also has a role in determining the requirements of the software product early. 
Moreover, it plays an important role in determining the framework/scope software project. In addition, it is the task of the Project Manager and the software to define and define the real and clear objectives pursued by the business organizations. The project development team should also hold more than one meeting and meeting with the owners and managers of business organizations to clarify and match the objectives of the business and the objectives of the software project in order to ease the control of the stages of the project. At the steps of the project manager and the program has the ability to review these goals to avoid failure The software product at the end As shown table (1),table (2), figure(1) and figure(2)

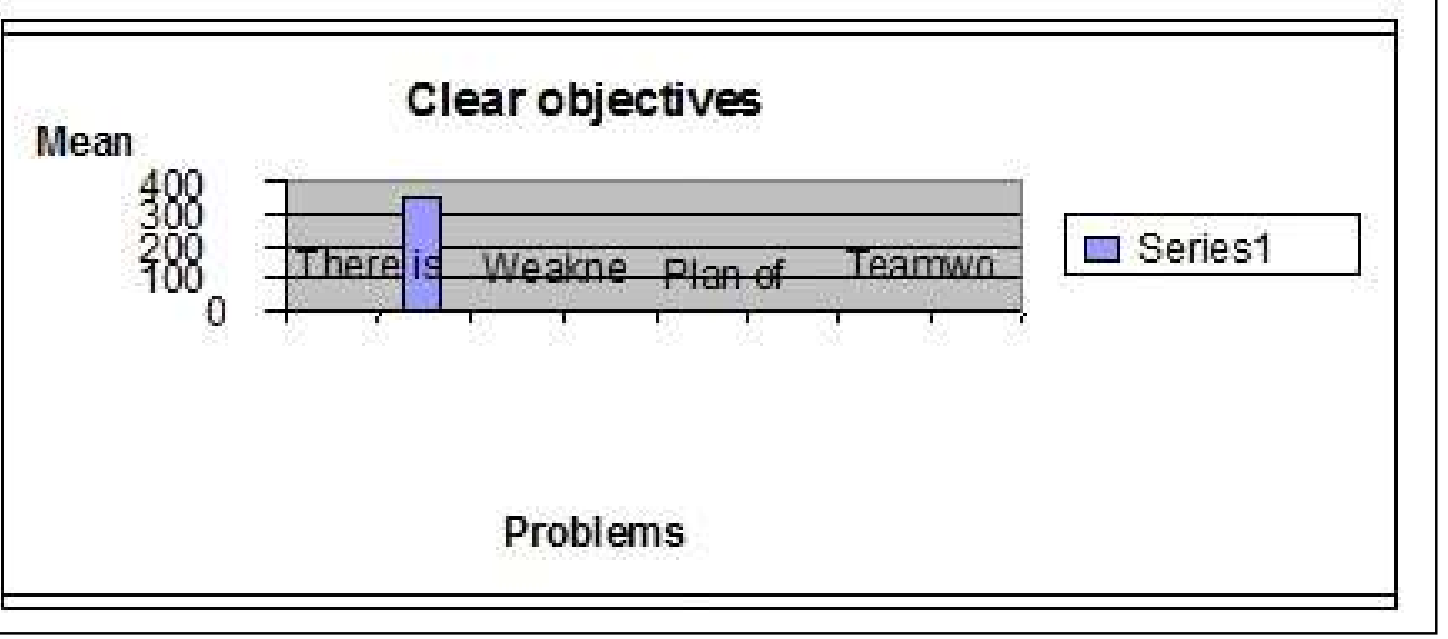

Figure 1. Mean for Clear Business Objectives according to questionnaire

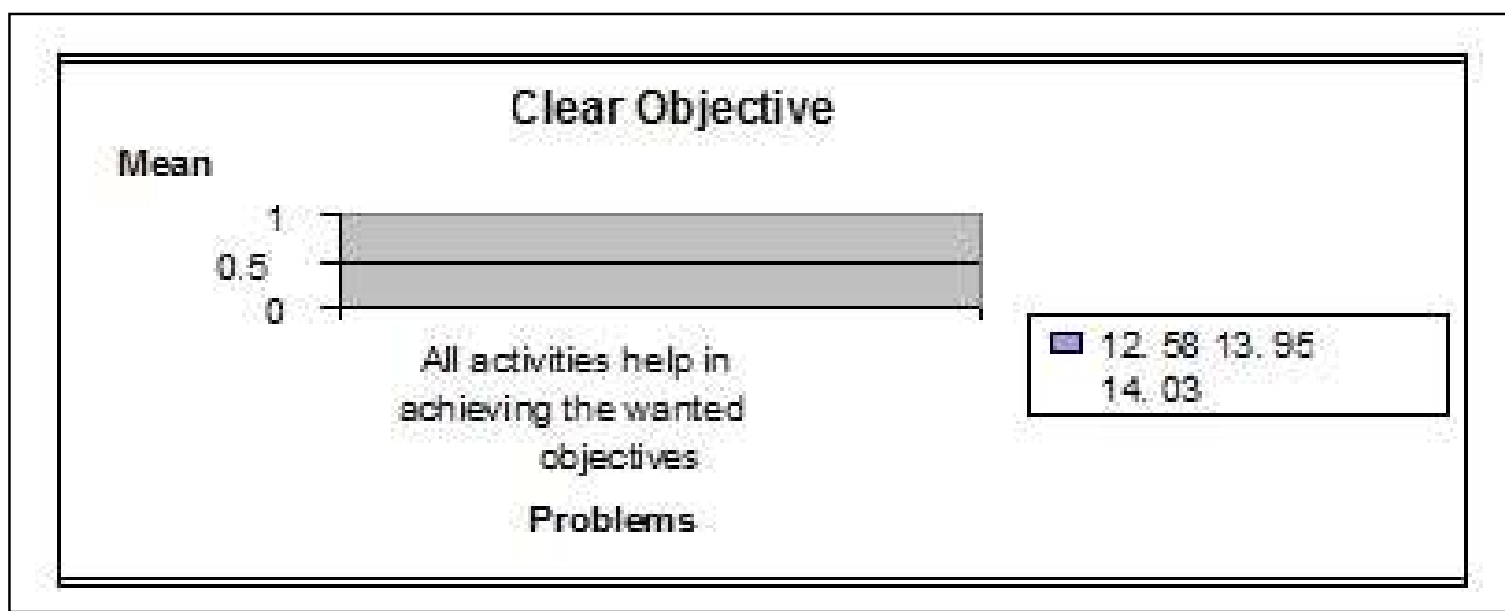

Figure 2. Clear objectives according to interview

\section{Recommendations:}

Based on the previous studies and the field study, this study concluded with a set of recommendations, which we specify as follows, knowing that any work is not lacking.

\subsection{Identify and define business objectives.}

A) To define the objective of the organization's work, we need to identify and define the basic motives of the work. There should be an informal description of the objectives of the work and the logic that leads us to the goal setting. Use the hypotheses. For example, the organization wants to maintain its position in the market there should be a focus on customer satisfaction.

B) The objective of the work must be formal, so that it can be easily filled through the objective model of the organization and thus a link with the sub-goals that lead to achieving the main goal with ease and pleasure

C) Define the standards and specifications upon which the objective of the work is evaluated, and all the models and criteria required by the assessment of that objective. 


\subsection{Determine the correct and appropriate strategic decision set}

A) We need to define the list of strategies

B) Choose the appropriate strategy in light of the organization's potential.

\section{Select the right software objectives}

A) We must ascertain the implications of choosing a strategy for software development and design. In order to test reliability, we must examine and test programs and processes.

B) We must determine the objective, taking into account the feasibility, cost and benefits of each of the objectives of the program, and here it should be noted that context factors and hypotheses help in the process of determining and choosing the right target/goal.

C) The software development team should formalize the goal of the program, a process similar to formalizing the objectives of the work.

D) Determines the exact outputs required from the system

E) Make sure that the inputs you enter the system in order to achieve the objectives of the required software product

F) Develop a control and control plan for the project to serve the software project by specifying the outputs required of the software producer to implement exactly

G) Project observation and objective improvement to serve project success through:

A. Updating the plan according to developments in the project

B. Check and check the changes that occur in the project during its implementation

C. Accept the changes that help the product and project succeed in general

D. Rejection of changes that help people rather than goals

E. review the plan periodically to serve the project objectives

\section{References:}

Alter, A. 2008. Tuning tech to business. Baseline, (80):40-41.

Becker, S.A. and Bostelman, M.L. "Aligning Strategic and Project Measurement Systems", IEEE Software, May/June 1999, pp. 46-51.

Boehm, B. and Ross, R. 1989. Theory-W Software Project Management Principles and Examples. IEEE Transactions on Software Engineering. Vol 15[7],902-916.

Buglione L. and Abran A. "Balanced Scorecards and GQM: What are the Differences?" Proceedings of FESMAAEMES Software Measurement Conference, October 2000.

Brown, I. \& Motjolopane, I. 2005. Strategic business-IT alignment, and factors of influence: A case study in a public tertiary education institution: Reviewed article. South African Computer Journal, (35):20-28.

Chrissis, M., Konrad, M., and Shrum, S. CMMI ${ }^{\circledR}$ Guidelines for Process Integration and Product Development, Addison-Wesley, 2007.

Chen, L. 2010. Business-IT alignment maturity of companies in China. Information \& Management, 47(1):9-16.

Cohen, J.F. \& Toleman, M. 2006. The IS-business relationship and its implications for performance: An empirical study of South African and Australian organisations. International Journal of Information Management, 26(6):457-468.

Jorfi, S., Nor, K. \& Najjar, L. 2011a. Assessing the impact of IT connectivity and IT capability on IT-business strategic alignment: An empirical study. Computer and Information Science, 4(3):76-87.

http://www.standishgroup.com, Accessed from aabfs website at 31/8/2018

Karpovsky, A. \& Galliers, R.D. 2015. Aligning in practice: from current cases to a new agenda. Journal of Information Technology, Advance Online Publication (AOP):1.

Kruger, W. 2012. Strategic business-IT alignment of application software packages: Bridging the information technology gap. South African Computer Journal, 49:1-11.

Mpazanje, F., Sewchurran, K. \& Brown, I. 2013. Rethinking Information Systems Projects using Actor-Network Theory - Perspectives from a Developing Country. The Electronic Journal of Information Systems in Developing Countries, 58(7):1-32.

Parkinson, J. 2002. Step by Step. CIO Insight, (15):98. 